\title{
Outcome of fetuses with heart disease diagnosed in utero
}

Marianne Eronen

\begin{abstract}
Objective-To review the outcomes of 193 fetuses with cardiac abnormalities detected by echocardiography.

Methods-A total of 422 fetuses between 16 and 41 gestational weeks, referred to paediatric cardiologists for detailed echocardiography, were included in this study.

Results-Structural heart defects were found in $55(28 \%)$, isolated arrhythmia in 105 (54\%), and other non-structural abnormalities (dilated cardiomyopathy, hypertrophic cardiomyopathy, aneurysm of the foramen ovale, isolated pericardial effusion or echogenic foci) in $33(17 \%)$ of 193 fetuses. Total mortality was $26 \%$. The prognosis was poor in fetuses with structural heart defects; 37 of 55 cases $(67 \%)$ died in utero or postnatally. Chromosomal abnormality was associated with structural heart defect in $38 \%$ of fetuses, of whom 38\% died. Among fetuses with isolated arrhythmia survival was $95 \%$. Poor outcome was associated with complete heart block $(n=14)$ in $2(14 \%)$ fetuses with hydrops and heart rate of less than 55 per minute, and with supraventricular tachycardia $(n=21)$ in three $(14 \%)$ neonates delivered prematurely at a mean gestational age of 33 weeks. Furthermore, nine of 12 fetuses $(75 \%)$ with structural heart defects and arrhythmia died. Among fetuses with non-structural cardiac abnormalities, survival was $73 \%$. Poor outcome was evident in fetuses with dilated cardiomyopathy in eight of 13 $(62 \%)$ and with hypertrophic cardiomyopathy in one of eight $(13 \%)$ of cases.

Conclusions-Factors associated with a poor prognosis were: structural heart defect associated with chromosomal abnormality or arrhythmia, congestive heart failure associated with supraventricular tachycardia or complete heart block, especially if delivery occurs preterm; and fetal hydrops with congestive heart failure and atrioventricular valve regurgitation. (Arch Dis Child 1997;77:F41-F46)
\end{abstract}

Hospital for Children and Adolescents, Division of Pediatric Cardiology, University of Helsinki,

Stenbackinkatu 11, 00290 Helsinki,

Finland

M Eronen

Correspondence to: Dr Marianne Eronen.

Accepted 30 January 1997
Notable exceptions are the atrial septal defect, because of the extreme thinness and the presence of the patent foramen ovale of the atrial septum in the fetus, and the arterial duct, which is a normal finding. Some defects can also evolve or progress during fetal life, making a definitive diagnosis early in gestation difficult. ${ }^{7}$ Prenatal diagnosis not only allows for planned management of the heart disease prenatally and postnatally, but also allows the families to consider the option of termination of pregnancy for severe defects.

Echocardiographic assessment of fetal arrhythmias is usually accomplished using M-mode and Doppler techniques. Echocardiography not only establishes the kind of arrhythmia present but can also identify associated structural and functional heart disease as well. Fetal congestive heart failure is diagnosed when tissue perfusion of the fetus is inadequate, characterised by cardiomegaly, atrioventricular valve regurgitation, and abnormal venous velocities. ${ }^{8}$ The presence of fetal congestive heart failure is also characterised by fetal hydrops in association with either tachycardia or bradyarrhythmia, and results in a very poor prognosis. ${ }^{9-13}$

\section{Methods}

The study group comprised 422 fetuses between 16 and 41 weeks gestational age that had been referred to a paediatric cardiologist for detailed echocardiology between January 1983 and December 1995 at the Children's hospital, University of Helsinki. The indications for referral were: a strong family history of congenital heart disease; fetal heart arrhythmia; abnormal four-chamber view; extracardiac malformation; fetal hydrops; and other conditions in which the risk of cardiac abnormality was increased-for example, maternal diabetes, chromosomal abnormality, or cardiac teratogen.

The fetal heart was examined using two dimensional guided, pulsed, and continuous wave Doppler equipment (Advanced Technology Laboratories $600 \mathrm{MK}$, Toshiba SSH 65 A and Acuson 128 Color Doppler system) with a $3.5 \mathrm{MHz}$ or $5 \mathrm{MHz}$ transducer. Two dimensional imaging was obtained from five approaches including four-chamber, fivechamber, long axis, short axis and arch views. The studies were judged to be of adequate diagnostic quality if the following were defined: cardiac rhythm; cardiac situs; ventricular and atrial chambers; valves; and the aortic and pulmonary arterial connections to the heart and aortic and ductal arches. Colour and pulsed or 
Table 1 Indications for fetal echocardiography and results

\begin{tabular}{|c|c|c|c|}
\hline \multirow[b]{2}{*}{ Indication } & \multirow[b]{2}{*}{$\begin{array}{l}\text { No (\%) of } \\
\text { fetuses }(n=422)\end{array}$} & \multicolumn{2}{|c|}{ No (\%) of fetuses with abnormal condition $(n=193)$} \\
\hline & & $\begin{array}{l}\text { Structural congenital } \\
\text { heart disease }\end{array}$ & $\begin{array}{l}\text { Non-structural cardiac } \\
\text { abnormality }\end{array}$ \\
\hline Family history & $145(34)$ & $3(2)$ & $5(3)$ \\
\hline Previous child & 126 & & \\
\hline Maternal & 15 & & \\
\hline Other & 4 & & \\
\hline Arrhythmia & $144(34)$ & $7(5)$ & $106(74)$ \\
\hline Abnormal four-chamber view & $40(9)$ & $28(70)$ & $2(5)$ \\
\hline Fetal hydrops & $17(4)$ & $1(6)$ & $9(53)$ \\
\hline Maternal diabetes & $17(4)$ & $0(0)$ & $5(29)$ \\
\hline Extracardiac malformations & $12(3)$ & $4(33)$ & $2(17)$ \\
\hline Chromosomal abnormality & $10(2)$ & $6(60)$ & $0(0)$ \\
\hline Small for gestational age & $8(2)$ & $3(38)$ & $0(0)$ \\
\hline Pregnancy induced hypertension & $7(2)$ & $0(0)$ & $0(0)$ \\
\hline Polyhydramnios & $7(2)$ & $1(14)$ & $3(43)$ \\
\hline Miscellaneous & $15(4)$ & $2(13)$ & $6(40)$ \\
\hline Twin-twin transfusion & 8 & 0 & 4 \\
\hline Oligohydramnios & 1 & 1 & 0 \\
\hline Thoracopagus & 1 & 1 & 0 \\
\hline Acardiac fetus & 1 & 0 & 1 \\
\hline Maternal hyperthyroidism & 1 & 0 & 0 \\
\hline Exposure to ketoprofen & 1 & 0 & 0 \\
\hline Exposure to lithium & 1 & 0 & 0 \\
\hline Maternal HIV, antiviral medication & 1 & 0 & 1 \\
\hline Total & 422 & $55(13)$ & $138(33)$ \\
\hline
\end{tabular}

continuous wave Doppler echocardiography were carried out when a clinically significant structural defect was suspected by imaging. The type of arrhythmia was analysed using an M-mode echocardiogram at the atrial and ventricular levels. The non-structural cardiac abnormalities were identified as dilatated cardiomyopathy, hypertrophic cardiomyopathy, aneurysm of the foramen ovale, and isolated pericardial effusion or echogenic foci. All studies were performed using the standard transabdominal approach. The abnormal studies were recorded on videotape for subsequent playback and analysis.

Personal data were recorded for each mother. After counselling, she returned to the referring hospital for further care unless it was felt that the fetus would benefit from ongoing combined cardiac/obstetric management, in which case, management was continued at the Children's Hospital. The progress and outcome of each pregnancy (including those where no abnormality was detected) were followed up, and where appropriate, post mortem examinations were performed. In most of these cases the heart was examined at the Children's Hospital. Follow up lasted 12 months.

\section{Results}

Among the 422 fetuses examined by a paediatric cardiologist, 193 (46\%) had cardiac abnormalities. Of the 40 mothers referred because of the obstetrician suspecting a structural heart defect, $28(70 \%)$ were confirmed as abnormal. The reasons for the referral and the findings are shown in table 1 .

The commonest indications for referral were a family history of complete heart disease (34\%) and arrhythmias (34\%). Three fetuses (2\%) scanned for family history were found to have structural heart defects. All cases were siblings. Of the 34 families with a history of left heart hypoplasia $(\mathrm{LHH})$, one $(3 \%)$ fetus had the same defect. Five mothers also had fetuses with arrhythmia (three with premature atrial contractions and two with sinus bradycardia).

Among 55 fetuses with structural heart defect, poor outcome was seen in 37 cases $(67 \%)$. The type of heart defect, presence or absence of chromosomal abnormality, treatment and outcome of the affected fetuses are described in table 2 . Total fetal mortality was $15 \%$; four fetuses were aborted and four fetuses died in utero. Twenty nine of the 55 (53\%) died neonatally (table 2). A total of 12

Table 2 Structural fetal heart disease, treatment, and outcome

\begin{tabular}{|c|c|c|c|c|c|c|c|}
\hline \multirow[b]{2}{*}{ Diagnosis } & \multirow{2}{*}{$\begin{array}{l}\text { No (\%) of } \\
\text { patients }\end{array}$} & \multirow{2}{*}{$\begin{array}{l}\text { Chromosomal } \\
\text { abnormality }\end{array}$} & \multirow{2}{*}{$\begin{array}{l}\text { Fetal death } \\
\text { (aborted) }\end{array}$} & \multirow{2}{*}{$\begin{array}{l}\text { Neonatal } \\
\text { death }\end{array}$} & \multicolumn{3}{|l|}{ Operated } \\
\hline & & & & & $<1$ month of age & 1-3 months of age & $>3$ months of age \\
\hline Ventricualr septal defect & $12(22)$ & 11 & $3(1)$ & 6 & 0 & 1 & 2 \\
\hline Left heart hypoplasia & $11(20)$ & 2 & $1(1)$ & 10 & 0 & 0 & 0 \\
\hline Atrioventriculoseptal defect & $8(15)$ & 5 & $1(1)$ & 0 & 1 & 1 & 5 \\
\hline Univentricular heart & $7(13)$ & 1 & $2(1)$ & 3 & 2 & 0 & 0 \\
\hline Double outlet right venticle & $3(5)$ & 1 & 0 & 2 & 2 & 0 & 0 \\
\hline Truncus arteriosus & $2(4)$ & 1 & 1 & 1 & 0 & 0 & 0 \\
\hline Tetralogy of Fallot & $2(4)$ & 0 & 0 & 0 & 0 & 0 & 2 \\
\hline Intracardiac tumour & $2(4)$ & 0 & 0 & 1 & 1 & 0 & 0 \\
\hline Pulmonary stenosis & $2(4)$ & 0 & 0 & 1 & 1 & 0 & 0 \\
\hline Ectopia cordis & $1 \quad(2)$ & 0 & 0 & 1 & 1 & 0 & 0 \\
\hline Single heart, conjoined twins & 1 (2) & 0 & 0 & 1 & 0 & 0 & 0 \\
\hline Ebstein's anomaly & 1 (2) & 0 & 0 & 1 & 0 & 0 & 0 \\
\hline Endocardial fibroelastosis & 1 (2) & 0 & 0 & 1 & 0 & 0 & 0 \\
\hline Mitral valve dysplasia & 1 (2) & 0 & 0 & 1 & 0 & 0 & 0 \\
\hline Atrial septal defect & $1 \quad(2)$ & 0 & 0 & 0 & 0 & 0 & 1 \\
\hline Total & 55 & 21 & $8(4)$ & 29 & 8 & 2 & 10 \\
\hline
\end{tabular}


Table 3 Fetal arrhythmias, frequency of treatment, and outcome

\begin{tabular}{|c|c|c|c|c|c|c|c|}
\hline \multirow[b]{2}{*}{ Type of arrhythmia } & \multirow{2}{*}{$\begin{array}{l}\text { No (\%) of } \\
\text { patients } \\
(n=125)\end{array}$} & \multicolumn{2}{|c|}{ Drug treatment } & \multirow[b]{2}{*}{ Pacemaker } & \multirow{2}{*}{$\begin{array}{l}\text { Structural } \\
\text { heart } \\
\text { disease }\end{array}$} & \multicolumn{2}{|c|}{ Deaths } \\
\hline & & In utero & Postnatally & & & Fetal & Neonatal \\
\hline Premature atrial contractions & $68(54)$ & 0 & 4 & 0 & 3 & 0 & 2 \\
\hline Supraventricular tachycardia & $21(17)$ & 18 & 16 & 0 & 0 & 0 & 3 \\
\hline Atrioventricular block & $18(14)$ & 2 & 5 & 13 & 4 & 2 & 3 \\
\hline Sinus bradycardia & $8(6)$ & 0 & 0 & 0 & 2 & 1 & 1 \\
\hline Premature ventricular contractions & $6(5)$ & 0 & 3 & 0 & 3 & 1 & 1 \\
\hline Sinus tachycardia & $4(3)$ & 0 & 0 & 0 & 0 & 0 & 0 \\
\hline Total & 125 & 20 & 28 & 13 & 12 & 4 & 10 \\
\hline
\end{tabular}

Table 4 Non-structural fetal heart abnormalities: aetiology and outcome

\begin{tabular}{|c|c|c|c|c|}
\hline \multirow[b]{2}{*}{ Abnormality } & \multirow{2}{*}{$\begin{array}{l}\text { No (\%) of } \\
\text { patients }\end{array}$} & \multirow[b]{2}{*}{ Aetiology $(n=)$} & \multicolumn{2}{|l|}{ Deaths } \\
\hline & & & Fetal (aborted) & Neonatal \\
\hline \multirow[t]{14}{*}{ Dilated cardiomyopathy } & $13(39)$ & Hydrops fetalis (5) & & \\
\hline & & Maternal anaphylactic reaction (1) & 1 & \\
\hline & & Renal agenesia (1) & & 1 \\
\hline & & Non-immunogenic (1) & & 1 \\
\hline & & Rhimmunisation (1) & & \\
\hline & & Pulmonary hypoplasia (1) & & \\
\hline & & Pulmonary adenomatous malformaltion (1) & $1(1)$ & \\
\hline & & Twin-twin trandfusion syndrome (1) & & \\
\hline & & Polyhydramnios, exposure to indomethacin (1) & & \\
\hline & & Perinatal infection (1) & & 1 \\
\hline & & Chorionangioma (1) & & 1 \\
\hline & & Arteriovenous fistula (1) & & 1 \\
\hline & & Sacrococcyceal teratoma (1) & & 1 \\
\hline & & Acardiac fetus (1) & & \\
\hline \multirow[t]{4}{*}{ Hypertrophic cardiomyopathy } & $8(24)$ & Maternal diabetes (5) & & \\
\hline & & Twin-twin transfusion syndrome (1) & & \\
\hline & & Non-immunogenic hydrops (1) & & 1 \\
\hline & & Polyhydramnios, duodenal atresia (1) & & \\
\hline Aneurysm of the foramen ovale & $6(18)$ & Unknown aetiology, arrhythmia (6) & & \\
\hline \multirow[t]{3}{*}{ Isolated pericardial effusion } & $4(12)$ & Twin-twin transfusion syndrome (2) & & \\
\hline & & Maternal HIV, antiviral medication (1) & & \\
\hline & & Non-immunogenic hydrops (1) & & \\
\hline Echogenic foci & $2(2)$ & Unknown aetiology (2) & & \\
\hline Total & 33 & & 2 & 7 \\
\hline
\end{tabular}

infants came to surgery at the age of 1 to 12 months with uncomplicated follow up. Chromosomal abnormality was detected in $38 \%$; trisomy $18(n=10)$, trisomy $21(n=6)$, trisomy 9 $(n=1)$, trisomy $13(n=1)$, trisomy $22(n=1), 2-P$ trisomy $21(n=1)$ and 3 B trisomy $2(n=1)$. A diagnosis of ventricular septal defect (VSD) or atrioventriculoseptal defect (AVSD) was particularly predictive of chromosomal abnormality $(\mathrm{P}=0.004)$. The largest group of infants who died neonatally were those with LHH (34\%). During the study period no medical or surgical intervention was attempted in these infants.

Of the eight fetuses who died in utero, four $(50 \%)$ were submitted to post mortem examination, including all terminations of pregnancy. Of the 29 fetuses who died as neonates, 26 $(90 \%)$ were examined post mortem. The predicted structural abnormality was correct in 28 fetuses $(93 \%)$ and partly correct in two fetuses (double outlet right ventricle and univentricular heart). Of the 229 fetal examinations with normal findings, two $(0.9 \%)$ minor abnormalities were not diagnosed (ASD and a small VSD). Both survived. No false positive diagnoses were made.

Of the 144 fetuses referred for cardiac arrhythmia, $106(74 \%)$ had arrhythmia. However, among the whole study population $(\mathrm{n}=422)$, fetal arrhythmia was detected in 125 $(30 \%)$ fetuses (table 3$)$. The most commonly noted arrhythmia was premature atrial contractions ( $54 \%$ of cases). Of these, poor outcome was evident in two fetuses (3\%) with a structural heart defect (one fetus with trisomy 13 and VSD and one fetus with Ebstein's anomaly). Five fetuses with aneurysm of the foramen ovale had a good outcome.

Supraventricular tachycardia (SVT) was detected in $17 \%$ of fetuses with arrhythmia with a median gestational age of 32 weeks (range 26 to 37 weeks). None of these fetuses had structural heart defects; one had aneurysm of the foramen ovale. Eighteen $(86 \%)$ of 21 fetuses were treated with antiarrhythmic medication in utero: digoxin $(n=8)$, digoxin combined with propranolol $(n=4)$, combined triple route (intravenous, intraperitoneal, and transplacental) administration of amiodarone $(n=2)$, digoxin combined with flecainide $(n=2)$, digoxin combined with quinidine $(n=1)$ and digoxin combined with verapamil $(n=1)$. There were no intrauterine deaths. However, three infants delivered prematurely by caesarean section died neonatally $(14 \%)$. The causes of death were cardiac failure accompanied by severe respiratory distress in two and severe cardiac failure in one. The mean gestational age at birth in the neonates with poor outcomes was significantly lower than in those with a good outcome (33 weeks vs 37 weeks; $\mathrm{P}=0.025)$. Of the 18 survivors, $15(83 \%)$ were given antiarrhythmic medication postnatally.

Among 18 fetuses with complete heart block, structural heart defects were found in four $(22 \%)$; two fetuses with hydrops were treated with digoxin in utero. Poor outcome was evident in five cases $(28 \%)$; two fetuses 


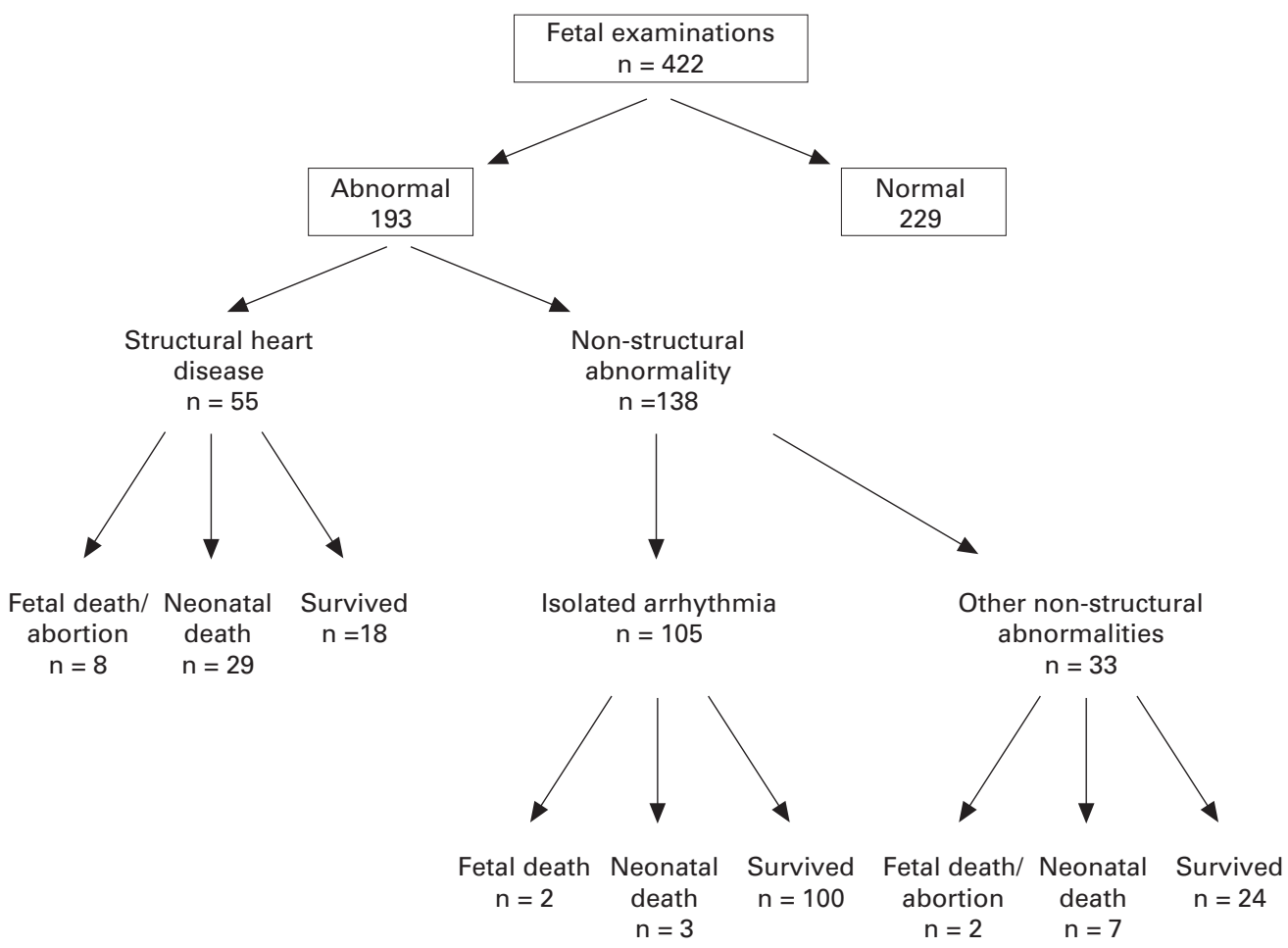

Figure 1 Outcome of 193 fetuses with heart disease diagnosed in utero.

(both with normal hearts and fetal ventricular rates of 38 to 55 per minute) and three neonates with structural heart disease died. Pacemakers were implanted in 13 of $16(81 \%)$ neonatal survivors. The criteria for pacemaker insertion were structural heart defect or a heart rate equal to or less than 70 beats per minute.

Sinus bradycardia (heart rate of less than 100 beats per minute) was associated with poor outcome in two cases (25\%) with structural heart defect. Two of six fetuses (33\%) with premature ventricular contractions died; both had trisomy 18 accompanied by structural heart defects (VSD and LHH). One neonate with intracardiac myxoma in the right atrium was successfully operated on. Fetuses with sinus tachycardia (heart rate of more than 180 beats per minute) had a good prognosis.

Non-structural fetal heart abnormalities, aetiology, and outcome are presented in table 4. Congestive heart failure with dilatation of one or both ventricles, combined with atrioventricular valve regurgitation, was associated with poor outcome in eight cases (62\%). Of 17 fetuses referred for maternal diabetes, five $(29 \%)$ had left ventricular wall or septal hypertrophy; none had structural heart defect. One infant with non-immunogenic hydrops and severe left ventricular hypertrophy died after birth in respiratory distress syndrome. Of four pregnancies with twin-twin transfusion syndrome, two fetuses had isolated pericardial effusion, one dilated cardiomyopathy and one hypertrophic cardiomyopathy. All survived; one twin infant needed several pericardial punctures after birth. Two fetuses with echogenic foci located within the chordae tendineae in left ventricle had uncomplicated follow up.

The outcome of the whole study population is presented in fig 1 .

\section{Discussion}

In this series of 193 fetuses with abnormal echocardiography poor outcome was evident in $26 \%$, of whom $3 \%$ were aborted. Structural heart disease diagnosed in utero had the poorest prognosis; $67 \%$ of fetuses died in utero or postnatally. Chromosomal abnormality was associated with structural heart defect in 38\% of fetuses, in $92 \%$ of fetuses with VSD, in $63 \%$ of fetuses with AVSD and in $18 \%$ of fetuses with LHH. A diagnosis of VSD or AVSD was therefore particularly predictive of chromosomal abnormality. In this study $38 \%$ of fetuses with an abnormal karyotype died. These findings confirm those of previous studies ${ }^{11415}$ and suggest that chromosomal evaluation of any patient with an abnormal fetal echocardiogram, regardless of the gestational age, should be carried out. Knowledge of the fetal karyotype permits well defined postnatal surgical intervention that may need to be adjusted if an abnormal karyotype is present.

Antenatal diagnosis of heart disease leads to earlier recognition of treatable abnormalities which might otherwise not be recognised until after the onset of symptoms or until death. ${ }^{16}$ When chromosomal abnormalities were excluded, all fetuses with Fallot's tetralogy or univentricular heart (UVH) and $50 \%$ of fetuses with double outlet right ventricle or intracardiac tumour survived surgery. Furthermore, $88 \%$ of fetuses with AVSD, including those with trisomy 21, survived heart surgery. However, $\mathrm{LHH}$ was associated with a mortality of $100 \%$, because no active intervention was attempted in these newborn infants during the study period.

The incidence of $2 \%$ structural heart defect in the same family is similar or lower than data reported by others. ${ }^{417}{ }^{18}$ Although the yield of 
abnormal results was low in this study group, the emotional benefit to the family of finding that their baby has a normal fetal heart, or of being prepared for delivery of a baby with an abnormal condition, is a valid reason for the fetal echocardiography.

In previous series about $15 \%$ of referrals have been for abnormalities of cardiac rhythm. ${ }^{47}$ In this study population fetal arrhythmia was detected in $30 \%$ of fetuses. As in previous reports, ${ }^{19}{ }^{19}$ the most commonly noted arrhythmias were premature atrial contractions affecting $54 \%$ of fetuses with arrhythmia. Several studies have shown that premature atrial contractions are self-limiting and carry a benign prognosis. ${ }^{19-21}$ However, in this study $4 \%$ had concomitant structural heart defect accounting for a total mortality of $3 \%$ of fetuses with premature atrial contractions. Furthermore, $50 \%$ of fetuses with premature ventricular contractions had structural heart defects. In light of these findings, a full fetal echocardiographic evaluation should be undertaken in all patients with premature atrial or ventricular contractions.

In several studies fetal complete heart block accompanied by structural heart disease has been associated with poor prognosis. ${ }^{10-12}$ The mortality of $75 \%$ in our series confirms this finding. The structural heart diseases associated with poor prognosis in this series were mitral valve dysplasia, $\mathrm{LHH}$, and UVH (double inlet right ventricle). Two fetuses with isolated complete heart block died. Both had bradycardia of less than 55 beats/min. This finding is similar to that of a recent study ${ }^{13}$ and proves that isolated complete heart block does not always have a good prognosis.

Fetuses with SVT accompanied by cardiac failure and hydrops have been treated with a variety of different pharmacological agents. ${ }^{22-26}$ In this series, a total of $86 \%$ of fetuses with SVT were treated with antiarrhythmic medication in utero. However, there were three neonatal deaths (14\%); all were delivered prematurely by caesarean section because of cardiac failure. Those who survived had a significantly higher gestational age at delivery. This agrees with previous studies which indicate that in utero treatment for SVT is preferable to premature delivery, especially if the lungs are immature. ${ }^{1922}$

A recent study showed that the prognosis is poor in fetuses with ascites, when cardiomegaly is also detected in the presence of atrioventricular valve regurgitation. ${ }^{27}$ In this study congestive heart failure with cardiomegaly was associated with a mortality of $62 \%$. In addition, four fetuses with twin-twin transfusion syndrome had decreased cardiac function or pericardial effusion and $29 \%$ of fetuses referred because of maternal insulin dependent diabetes had left ventricular wall or septal hypertrophy. ${ }^{28}{ }^{29}$ These findings suggest that all mothers with at risk pregnancies should receive a thorough fetal echocardiographic study to evaluate heart structure and function. ${ }^{30-33}$

In conclusion, whenever fetal echocardiography shows a structural heart defect, the presence of chromosomal abnormality and extracardiac malformation must be sought. When structural heart defect is associated with an abnormal karyotype, with the exception of 21-trisomy, fetal and neonatal mortality are high. When cardiac arrhythmia is associated with structural heart defect or congestive heart failure, direct or indirect medication of the fetus must be administrated as effectively as possible to avoid premature delivery. Fetuses with severe hydrops associated with congestive heart failure and atrioventricular valve regurgitation have a poor prognosis. When a prenatal diagnosis of structural, rhythmic, or functional abnormality is obtained the healthcare team can outline a management strategy to maximise the care and support given to the fetus, mother, and family.

1 Friedman AH, Copel J, Kleinman CS. Fetal echocardiography and fetal cardiology: Indications, diagnosis and management. Semin Perinatol 1993;1 17:76-88.

2 Copel JA, Kleinman CS. The impact of fetal echocardiography on perinatal outcome. Ultrasound Med Biol phy on perinatal

3 Copel JA, Pilu G, Green J, Hoppins JC, Kleinman CS. Fetal echocardiographic screening for congenital heart disease: the importance of the four-chamber view. Am $\mathcal{F}$ Obstet Gynecol 1987;157:648-55

4 Wheller JJ, Reiss R, Allen HD. Clinical experience with fetal echocardiography. Am f Dis Child 1990;144:49-53.

5 Wyllie J, Wren C, Hunter S. Screening for fetal cardiac malformations. Br Heart $\mathcal{F}$ (suppl) 1994;71:20-7.

6 Allan LD. Echocardiographic detection of congenital heart disease in the fetus: present and future. Br Heart 7 1995;74:103-6.

7 Hornberger LK, Sanders SP, Rein AJ, Spevak PJ, Parness IA, Colan SD. Left heart obstructive lesions and left ventricular growth in the midtrimester fetus. A longitudinal study. Circulation 1995;92:1531-8.

8 Hecher K, Campbell S, Doyle P, Harrington K, Nicolaided K. Assessment of fetal compromise by Doppler ultrasound investigation of the fetal circulation. Circulation 1995;91:129-38.

9 Baumann P, Copel JA, Kleinman CS. Management of the fetus with cardiac disease. Ultrasound $Q$ 1991;10:57-60.

10 Kleinman CS, Copel JA, Hobbins JC. Combined echocardiographic and Doppler assessment of fetal congenital atrioventricular block. Br f Obstet Gynaecol 1987;94:96774.

11 Wladimiroff JW, Stewart PA, Tonge HM. Fetal bradyarrhythmhmia: diagnosis and outcome. Prenatal Diagn 1988;8:53-7.

12 Baxi L, Bierman F, Ursell P. Evolution of complete heart block in a fetus and its perinatal management. Am F Perinatol 1987;4:348-51

13 Groves AMM, Allan LD, Rosenthal E. Outcome of isolated congenital complete heart block diagnosed in utero. Heart f 1996;75:190-4.

14 Davis GK, Farquhar CM, Allan LD, Crawford DC, Chapman MG. Structural cardiac abnormalities in the fetus: reliability of prenatal diagnosis and outcome. Br f Obstet Gynaecol 1990;97:27-31.

15 Wallgren EI, Landtman B, Rapola J. Extracardiac malformations associated with congenital heart disease. Eur $\mathcal{f}$ Cardiol 1978;7:15-18.

16 Abu Harb M, Hey E, Wren C. Death in infancy from unrecognized congenital heart disease. Arch Dis Child 1994;71:3-7.

17 Smythe JF, Copel JA, Kleinman CS. Outcome of prenatally detected cardiac malformations. $A m \quad \mathcal{f}$ Cardiol 1992;69:1471-5.

18 Azcarate MJM, Jimenez MQ. The technique of fetal echocardiography, with its indications and results in a selected population. Cardiol Young 1991;1:141-8.

19 Lingman G, Lundström N-R, Marsal K, Ohrlander S. Fetal cardiac arrhythmia. Acta Obstet Gynecol Scand cardiac arrhy

20 Southland DP, Richards J, Hardwick Ra, et al. Prospective study of fetal heart rate and rhythm pattern. Arch Dis Child 1980;55:506-9.

21 Stewart PA, Wladimiroff JW. Fetal atrial arrhythmias associated with recumdancy/aneurysm of the foramen ovale. $\mathcal{F}$ Clin Ultrasound 1988;16:643-50.

2 Kleinman CS, Copel JA, Weinstein EM, Santulli TV, Hobbins JC. In utero diagnosis and treatment of fetal supraventricular tachycardia. Semin Perinatol 1985;9:11329 .

23 Allan LD, Chita S, Maxwell D, et al. Use of flecainide in fetal atrial tachycardia. Br Heart $\mathcal{F}$ 1990;64:90-5.

24 Arnoux P, Seyral P, Llurens M, et al. Amiodarone and digoxin for refractory fetal tachycardia. Am $\mathcal{f}$ Cardiol 1987;59:167-72.

25 Dumesic DA, Silverman NS, Tobias S, et al. Transplacental cardioversion of fetal supraventricular tachycardia with procainamide. $N$ Engl $\mathcal{F}$ Med 1982;307:1128-31. 
26 Flack NJ, Zosmer N, Bennet PR, Vaugham J, Fisk NM Amiodarone given by three routes to terminate fetal atrial
flutter associated with severe hydrops. Obstet Gynecol flutter associated

27 Respondek M, Kaczmarek P, Pertynski T. Fetal echocardiography quidelines to predict survival of fetuses with ascites. Ultrasound Obstet Gynecol 1996;7:256-61.

28 Breitweser JA, Meyer RA, Sperling MA,Tsang RC, Kaplan S. Cardiac septal hypertrophy in hyperinsulemic infants. $\mathscr{f}$ Pediatr 1980;96:535-9.

29 Cooper MJ, Enderlein MA, Tarnoff H, Roge CL. Asemmetric septal hypertrophy in infants of diabetic mother. Fetal
echocardiography and the impact of maternal diabetic control. Am f Dis Child 1992;146:226-9.
30 Abu-Harb M, Wyllie J, Hey E,Richmond S, Wren C. Antenaltal diagnosis of congenital heart disease and Downs's syndrome: the potential effect on the practice of paediatric cardiology. Br Heart f 1995;74:192-8.

31 Shenker L, Reed Kl, Andersson CF, Kern W. Fetal pericardial effusion. Am f Obstet Gynecol 1989;160:1505-8.

32 Zosmer N, Bajoria R, Weiner E, Rigby M, Vaugham J, Fisk NM. Clinical and echographic features in utero cardiac NM. Clinical and echographic features in utero cardiac
dysfunction in the recipient twin in twin-twin transfusion dysfunction in the recipient twin in
syndrome. Br Heart $\mathcal{F}$ 1994;72:74-9.

33 Hecher K, Ville Y, Snijders R, Nicolaides k. Doppler studies of the fetal circulation in twin-twin transfusion syndrome. Ultrasound Obstet Gynecol 1995;5:318-24. 